\title{
Usefulness of convalescent plasma transfusion for the treatment of severely ill COVID-19 patients in Pakistan
}

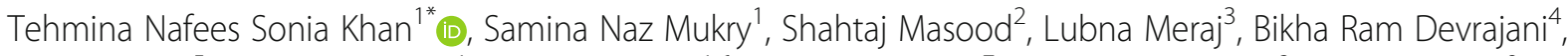
Javed Akram ${ }^{5}$, Naveena Fatima', Sidra Maqsood ${ }^{1,6}$, Ayesha Mahesar ${ }^{7}$, Roomana Siddiqui $^{8}$, Sadia Ishaque, Muhammad Bilal Afzal ${ }^{10}$, Sanam Mukhtar ${ }^{11}$, Sara Ahmed ${ }^{12}$, Arshi Naz and Tahir Sultan Shamsi ${ }^{1}$

\begin{abstract}
Background: Convalescent plasma(CP) was utilized as potential therapy during COVID-19 pandemic in Pakistan. The study aimed at appraisal of CP transfusion safety and usefulness in COVID pneumonia.

Methods: Single arm, MEURI study design of non-randomized open label trial was conducted in five centers. Patients werecategorized as moderately severe, severe, and critical. The primary endpoint was a) improvement in clinical status and change in category of disease severity; secondary endpoint was b) CP ability to halt disease progression to invasive ventilation. CP transfused to hospitalized patients. Statistical tests including median (interquartile ranges), Mann-Whitney U test, Fisher's exact test using SPSS ver. 23, ANOVA and Chi-square test were applied for the analysis of results parameters before and after CP treatment. SOFA score was applied for multiorgan failure in severe and critical cases.

Results: A total of 50 adult patients; median age 58.5 years (range: 29-92 years) received CP with infusion titers; median 1:320 U/mL (Interquartile range 1:80-1:320) between April 4 to May 5, 2020. The median time from onset of symptoms to enrollment in trial was 3 to 7 days with shortness of breath and lung infiltration as severity criterion. In 35 (70\%) recipients, oxygen saturation improved from 80 to 95\% within 72h, with resolution of lung infiltrates. Primary endpoint was achieved in 44 (88\%) recipients whereas secondary endpoint was achieved in 42 (84\%). No patient experienced severe adverse events. A high SOFA score $(\geq 7)$ correlated with deaths in severe and critical patients. Eight (16\%) patients expired due to comorbidities; cardiac arrest in 2 (4\%), multiorgan failure secondary to cytokine storm in 5 (10\%) and ventilator associated complications in 1 (2\%).
\end{abstract}

Conclusion: CP transfusion can be used as a safe and useful treatment in moderately severe and severe patients.

Trial registration: The trial registration number is NCT04352751 (https://www.irct.ir/search/result?query=IRCT202 00414047072N1). Trial Registration date is 28th April 2020.

Keywords: Convalescent CP recipient, Convalescent plasma (CP), COVID-19, SARS CoV2 infection, SOFA score

\footnotetext{
*Correspondence: dr_tehmina@yahoo.com; tehmina.nafees@nibd.edu.pk

${ }^{1}$ National Institute of Blood Diseases \& Bone Marrow Transplantation, Karachi,

Pakistan

Full list of author information is available at the end of the article
}

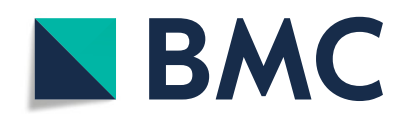

(c) The Author(s). 2021 Open Access This article is licensed under a Creative Commons Attribution 4.0 International License, which permits use, sharing, adaptation, distribution and reproduction in any medium or format, as long as you give appropriate credit to the original author(s) and the source, provide a link to the Creative Commons licence, and indicate if changes were made. The images or other third party material in this article are included in the article's Creative Commons licence, unless indicated otherwise in a credit line to the material. If material is not included in the article's Creative Commons licence and your intended use is not permitted by statutory regulation or exceeds the permitted use, you will need to obtain permission directly from the copyright holder. To view a copy of this licence, visit http://creativecommons.org/licenses/by/4.0/. The Creative Commons Public Domain Dedication waiver (http://creativecommons.org/publicdomain/zero/1.0/) applies to the data made available in this article, unless otherwise stated in a credit line to the data. 


\section{Introduction}

Severe acute respiratory syndrome corona virus 2 (SARS-CoV-2) is a novel member of Coronaviridae family [1]. It is a positive sense RNA beta-corona virus possibly evolved as a result of animal spill over from bats [2]. The infection surfaced in late 2019 and took the form of a pandemic. To-date the virus has infected 20 million people in 215 countries or regions resulting in 7.6 lacs deaths (https://www.worldometers.info/ coronavirus/> [Accessed 14 August 2020]. Although the mortality rate due to novel coronavirus disease (COVID19 ) is slightly low (17.5\%) compared to SARS (severe acute respiratory syndrome) and MERS (Middle East Respiratory Syndrome), the level of transmission is high which has resulted in recent pandemic of unprecedented consequences. No prophylactic or curative treatment options exist for COVID-19 at present [3]. As per recent trials, antivirals against HIV and other coronaviruses such as protease inhibitor combination lopinavir/ritonavir have failed to prove efficacy in the treatment of severe COVID-19 [4]. Although new antivirals like remdesivir is a promising candidate among other explored treatment options but the data on its safety and efficacy is still limited. Immune therapies such as the use of convalescent plasma $(\mathrm{CP})$ for the treatment of infectious diseases SARS, MERS, Ebola, Measles, polio, H1N1 influenza etc., has been proven effective for more than a century especially during emergency situations [5]. Under the current condition of medical emergency CP treatment has been listed as a possible investigational treatment option for severe and critical COVID-19 cases [6].

The mechanism of action of CP treatment is diverse involving the viral neutralization and clearance by direct inactivation and/or by enhancing humoral immune response to viral antigen. Complete viral clearance generally happens 12 to 20 days post- infection [7]. Therefore, the efficacy of CP therapy could be enhanced by its administration soon after appearance of usual disease symptoms [8]. The antagonistic and synergistic effect of steroid or other experimental drug therapies may alter the efficacy of CP therapy [9].

CP therapy has been strongly advocated by many researchers as a potential therapeutic option [10]. Elevated inflammatory markers including IL-6, ferritin, C-reactive protein and Lactate Dehydrogenase (LDH) as markers of tissue injury were proved to be good predictors of viral induced cytokinemia and compromised respiratory function as a result lung parenchymal damage in COVID-19 disease $[11,12]$. Interestingly, higher concentrations of IgG appeared earlier in severe COVID-19 female patients [13] but presence of anti-HLA/HPA/HNA antibodies in multiparous women discourage $\mathrm{CP}$ donation from female survivors to avoid the possible risk of transfusion related acute lung injury (TRALI) in recipients
[14]. Although the duration of persistence of anti-SARS$\mathrm{CoV}$-2antibodies in recovered patient plasma remains unknown but based on previous studies on MERS, SARS, and Ebola it suggested that CP could be collected for up to 6 months at an interval of every 14 days [13]. Asymptomatic COVID-19 patients recovered without hospitalization in general population may also be the suitable donors. The possible adverse events such as allergy to plasma components, coinfection, multiple organ failure, risk of thrombosis and volume overload should always be taken into account while prescribing CP therapy [15].

The purpose of this study was to explore feasibility of $\mathrm{CP}$ as an emergency investigational new treatment option in COVID-19 patients with severe to critical disease treated in different hospitals all over Pakistan.

\section{Materials and methods}

This MEURI (Monitored Emergency Use of Unregistered and Investigational Interventions), Nonrandomized open label trial was approved by the institutional review board (NIBD/RD-02/03-2020), National Bioethics Committee of Pakistan (NBC Registration No: NBC-472 COVID19-03), Drug Regulatory Authority of Pakistan (Registration No: F.NO.17-8/2020 DD (PS) and clinicatrials.gov (NIH ID: NCT04352751). It was conducted in accordance with Declaration of Helsinki 2000. In the initial period, hospitalized patients of covid-19 from April 4, 2020 to May 5, 2020 in five different hospitals across Pakistan were included. All recipients were above 18 years, and a written informed consent was obtained from each patient or a family member. The primary and secondary endpoint of this study were, a) improvement in clinical signs and symptoms and change in category of disease severity, b) ability of $\mathrm{CP}$ to halt disease progression leading to invasive ventilation, respectively. CP screening for Hepatitis B virus (HBV), Human Immunodeficiency Virus (HIV) was done by chemiluminescence assay using Abbot Architect while Hepatitis $\mathrm{C}$ virus (HCV) was screen by $\mathrm{HCV}$ nucleic acid testing (NAT) using artus ${ }^{\oplus}$ RG RT-PCR kit., using complete blood counts (CBC) samples of CP donors' and Rapid diagnostic test (RDT) and microscopy were used to screen malaria.

\section{Data collection}

Data was collected from the collaborative centers across Pakistan by clinical research associates through clinical report form (Fig. 1).

\section{Patient selection and intervention}

The Polymerase chain reaction (PCR) positive COVID-19 patients were categorized in three groups according to the guidelines of center for 


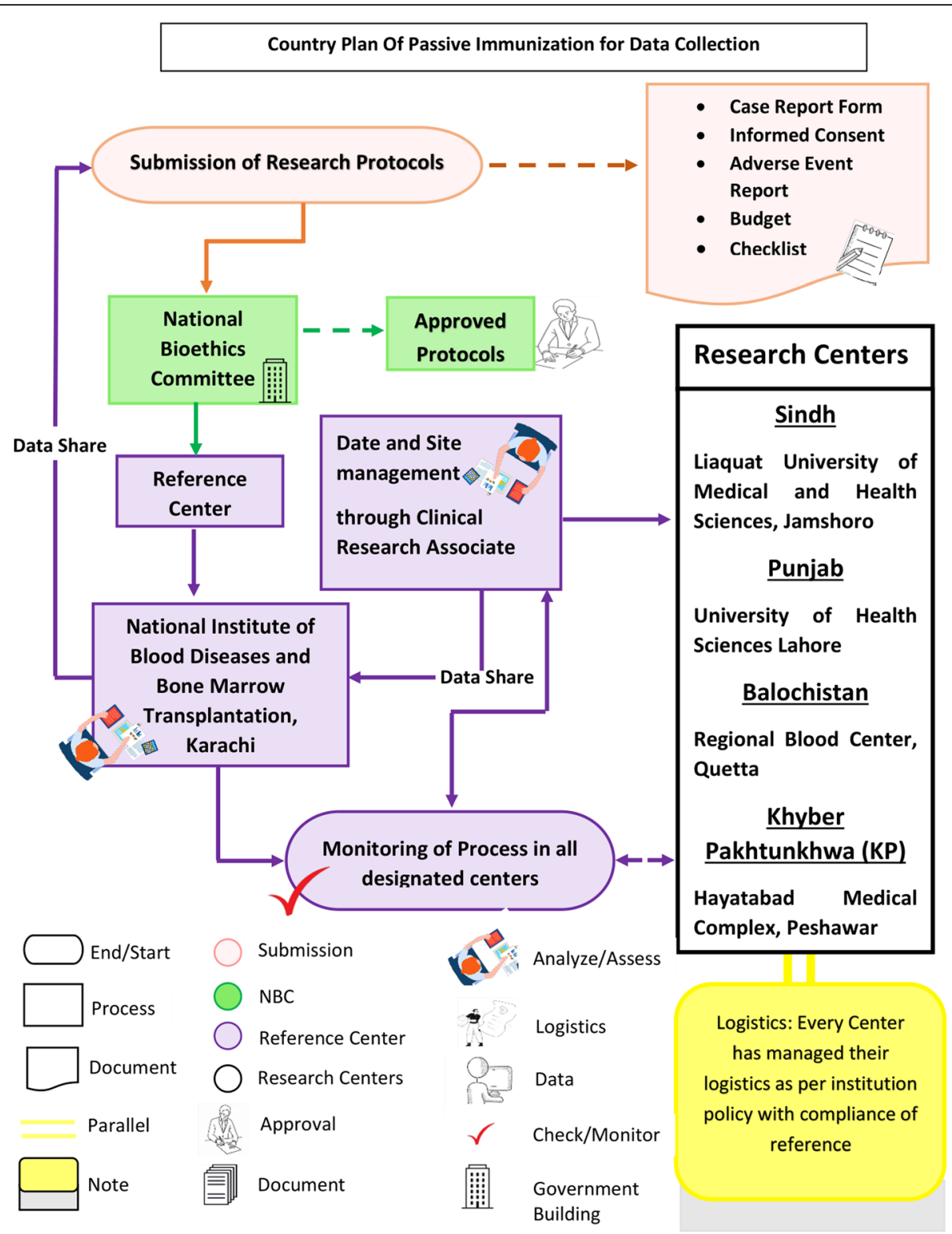

Fig. 1 The country plan for Passive immunization explains the entire process from submission of protocol for approval to site management, data sharing and monitoring of entire trial process in all authorized centers of transfusion across Pakistan

disease control and prevention (CDC) (cdc.gov). The moderately severe category was defined as i) shortness of breath, ii) respiratory rate $\geq 30$ breaths/minute, oxygen saturation $\leq 93 \%$ on room air along with lung infiltration of 20 to $40 \%$ within 24 to $48 \mathrm{~h}$ of hospital admission. Severe category included patients with respiratory rate $\geq 30$ breaths/ minute, oxygen saturation $\leq 93 \%$ on oxygen support and lung infiltrates $\geq 50 \%$ within 24 to $48 \mathrm{~h}$ of hospital admission. The last amongst three categories i.e. critical patients were in respiratory failure, shock and multiorgan failure $[16,17]$.

\section{Inclusion and exclusion criteria}

All PCR positive, hospitalized COVID-19 patients $\geq 18$ years of age, in all three COVID-19 disease categories were included in this study. The patients with history of allergic reaction to sodium citrate or with multi-organ failure secondary to cytokine storm on ventilator for more than two days and in sepsis were excluded. Patients who received tocilizumab / remdesivir also not included in this study. All admitted patients received supportive care, while some patients received antibiotic treatment, glucocorticoid, and oxygen support as per institutional treatment protocols. 


\section{Specimen collection}

Blood samples were drawn before $\mathrm{CP}$ transfusion for $\mathrm{CBC}$, biochemistry parameters including $\mathrm{LDH}$, Serum Ferritin, and coagulation test of D-Dimer. An ABO compatible CP was transfused in a single dose of $400 \mathrm{~mL}$ with approximated high IgG titers (median 1:320 U/mL) and low IgG titers $(<1: 160 \mathrm{U} / \mathrm{mL})$ was transfused to patients in 5-6h duration. World health organization (WHO) guidelines for the selection of a healthy blood donor was followed for convalescent plasma donors. The entire transfusion process was performed under supervision of clinicians at the respective hospitals with close monitoring for any possible adverse events during procedure. The vitals of every recipients before, during and after CP transfusion were recorded carefully. Both clinical and laboratory parameters were documented before and after $\mathrm{CP}$ transfusion to rule out any significant finding.

For the assessment of main outcome, vitals, status of saturation of oxygen on non-invasive and invasive mechanical ventilation, blood samples for laboratory investigations were obtained in 9 days post $\mathrm{CP}$ transfusion follow-ups.

A 6-points ordinal Sequential Organ Failure Assessment (SOFA) score was done for the evaluation of multiorgan failure and patients' outcome. (https://clincalc. com/IcuMortality/SOFA.aspx).

\section{Statistical analysis}

Median (interquartile ranges) were used to described continuous variables while comparison was done by Mann-Whitney U test; categorical variables were compared by Fisher's exact test between patient groups using SPSS ver. 23. ANOVA and Chi-square test were used to compare laboratory parameters before and after $\mathrm{CP}$ treatment.

\section{Results}

\section{General trait of participants}

A total of 50 COVID-19 PCR positive hospitalized patients were selected initially with male predominance i.e., 39(78\%) with a median age of 58.5 years (range: $29-$ 92 years). Of 50 patients, $15(30 \%)$ were moderatelysevere, $33(66 \%)$ were severe while $2(4 \%)$ were critical. The commonest symptoms observed at the onset of disease was shortness of breath (98\%) body aches $(12 \%)$ and fever $(8 \%)$. All patients were on broad spectrum antibiotics due to suspected bacterial infections as per institutional policy. CP was transfused in all patients with variable titers; Median 1:320, including high titers (1: 160-1:320 U/mL) CP infusion done in 31 non- intubated subjects $(62 \%)$ of severe group and $2(4 \%)$ in intubated critical. The low titer $(1: 80-1: 160 \mathrm{U} / \mathrm{mL}) \mathrm{CP}$ was transfused in non-intubated category of moderately severe
15(30\%) and severe 2(4\%). Total 27 recipients of high titer plasma out of 31 showed early betterment in disease status in severe category, with 18 out of 27 patients showing response in first $72 \mathrm{~h}$ of infusion. The remaining 9 recipients were elderly patients in severe group transfused later (after 3-7 days) and they had delayed clinical improvement. The remaining four recipient who initially manifested good progress; expired later due to cardiac disease and organ failures secondary to comobidities in severe group. One patient in critical group also survived. An overall survival rate of $>75 \%$ was achieved in recipients of high titer $\mathrm{CP}$ infusion within severe disease group. Altogether, 17 recipients of low titer CP i.e., 15 in moderately severe group and and two patients with severe COVID-19 disease manifested very promising results in recipient's recovery. No moderate to severe adverse reactions were observed in any of the recipients (Table 1 ).

\section{Clinical and laboratory parameters in $\mathrm{CP}$ recipients}

Significantly elevated levels of ferritin, C-reactive protein and D-dimer were found in all three disease categories of COVID-19 patients (Table 2). Low hemoglobin was noted only in critical patients $(9.4 \pm 3.9 \mathrm{~g} / \mathrm{dL})$. High WBC counts in $25(50 \%)$ along with raised ANC (absolute neutrophil counts) and lymphopenia in $20(40 \%)$ before $\mathrm{CP}$ therapy. However, the average platelets were within normal range both pre-and post $\mathrm{CP}$ therapy. None of the recipients had malaria, HIV, HBV, HCV infection or any sexually transmitted disease.

\section{Post CP transfusion response (72 hours)}

A marked improvement in $\mathrm{SaO}_{2}$ level i.e., from $80 \%$ of $\mathrm{SaO}_{2}$ to $95 \%$ was recorded in CP recipients. The respiratory rate of $\geq 30$ breaths/minutes in $31(62 \%)$ out of 50 , strikingly subsided to normal during first 3 days. A marked decline was also observed in markedly raised pre-CP inflammatory markers specifically ferritin;(Pre CP: Median 350 (409-1415) in moderately severe group (Post-CP: Median 250;(IQR 220-353) $(p<0.038)$ and in severe patients (Pre-CP: Median 1091 (666-2254) (PostCP; $241(150-427)$ and $(p<0.011)$. Also C-reactive protein $(p<0.030)$ and $(p<0.014)$ in first two disease categories respectively showed decrease along with Ddimer values in severe and critical patients, over the period of $72 \mathrm{~h}$ (Fig. 2).

Initial radiological findings supported symptoms of acute respiratory distress syndrome (ARDS) with bilateral presentation of opacities in most patients affecting the middle and lower zones. It was interesting to note that apparent absorption of interstitial pneumonia was observed as early as 4 days post CP in most patients (Fig. 3). 
Table 1 Demographic and clinical information of COVID-19 patients with and without underlying medical conditions

\begin{tabular}{|c|c|c|c|c|}
\hline Demographics & Moderate $(\mathrm{N}+15)$ & Severe $(N=33)$ & Critical $(N=2)$ & $p$-value \\
\hline Age (years) & $63.06 \pm 15.1$ & $54.48 \pm 13.2$ & $66.0 \pm 2.82$ & $0.101^{a}$ \\
\hline \multicolumn{5}{|l|}{ Sex } \\
\hline Male & 11 & 26 & 2 & \multirow[t]{2}{*}{$0.682^{b}$} \\
\hline Female & 04 & 07 & 0 & \\
\hline Duration of admission (days) & $8.8 \pm 5.4$ & $11.8 \pm 7.0$ & $18.5 \pm 12.0$ & $0.116^{\mathrm{a}}$ \\
\hline Smoking status & 1 & 1 & 1 & $0.025^{* b}$ \\
\hline Co-morbids & 8 & 23 & 2 & $0.316^{b}$ \\
\hline Ventilator & 0 & 2 & 2 & $0.000^{* b}$ \\
\hline \multicolumn{5}{|l|}{ Presenting complains } \\
\hline Fever & 1 & 2 & 1 & $0.082^{b}$ \\
\hline $\mathrm{SOB}$ & 15 & 33 & 1 & $0.000^{* b}$ \\
\hline Cough & 0 & 3 & 0 & $0.440^{b}$ \\
\hline Bodyaches & 3 & 2 & 1 & $0.093^{b}$ \\
\hline Respiratory rate $\geq 30 / \mathrm{min}$ & 6 & 27 & 1 & $0.014^{* b}$ \\
\hline Arterial blood oxygen saturation $\leq 93 \%$ & 10 & 27 & 1 & $0.355^{\mathrm{b}}$ \\
\hline Lung infiltrates $>50 \%$ within 24 to 48 & 5 & 20 & 1 & $0.215^{\mathrm{b}}$ \\
\hline
\end{tabular}

ane-way ANOVA

${ }^{\mathrm{b}}$ Chi-square test

*Significant value

Significantly improved LDH values $(p=0.043)$ also confirmed hepatic improvements among $\mathrm{CP}$ recipients. Aspartate aminotransferase (AST) also improved with $\mathrm{CP}$ treatment. A gradual decline seen in WBC, ANC with further improved lymphocytes counts over the period of 5-9 days post $\mathrm{CP}$ transfusion follow-up (Table 2).

\section{Correlation between comorbidities and $\mathrm{CP}$ transfusion}

Underlying co-morbidities were observed in 33 (66\%) $\mathrm{CP}$ recipients in all three categories including asthma in $1(2 \%)$, malignancy in $1(2 \%)$, diabetes in $5(10 \%)$, hypertension in $10(20 \%)$, diabetes + hypertension in $13(26 \%)$ and $03(6 \%)$ had hypertension +ischemic heart disease (IHD). Three male recipients with severe COVID-19 had a history of smoking (Table 1). Four out of 5 diabetics got better and discharged after CP therapy; one patient died due to comorbidity and ventilator related complication in severe disease category. Nine (18\%) patients had hypertension and got discharged after achieving primary and secondary endpoints, two patients with hypertension and ischemic heart disease also expired in severe disease group. 11 (22\%) out of 13 patients of diabetes + hypertension improved clinically, and $2(4 \%)$ patients died because of associated heart disease and renal failure in severe disease group. One patient with malignancy; later shifted on ventilator also expired in severe group whereas asthmatic patient significantly improved after CP infusion. One patient in moderately severe group expired due to sudden cardiac arrest in the absence of any known preexisting comorbid.

\section{SOFA score}

The 6-point ordinal SOFA scoring of all patients was calculated and it was observed that six recipients who expired later had a high score $>6$ other than those two patients who died of cardiac and malignancy issues and had sofa score $<6$. These six patients were shown to have high percentage of estimated mortality. One recipient out of six subjects was already on ventilator. The remaining five patients expired due to cardiac arrest and multi organ failure secondary to cytokine syndrome and other associated comorbid. The calculated score in recipient on ventilator and in multi organ failure was 7-10 points and in non-vent recipients it was 4-7 points.

\section{Primary and secondary end points achieved}

Out of 50 recipients, 42 (84\%) patients, achieved both primary and secondary outcomes of disease severity reversal, clinical improvement and subsided laboratory parameters to baseline values thereby preventing disease progression. The remaining two patients who achieved primary endpoint initially (4\%) expired due to sudden cardiac arrest and malignancy. Two subsequent negative PCR were obtained within 9 days for all discharged CP recipient. The overall duration of admission was shorter in patients with no underlying medical condition i.e., 318 days vs 3-25 days (for patients with existing comorbid). The $35(70 \%)$ patients who received $\mathrm{CP}$ within 7 days of a positive COVID-19 RT-PCR (or onset of their illness) recovered within 13 days (median $=9$ days) as compared to those who received it late. 
Table 2 Changes in Lab findings and efficacy of CP in comparison to other experimental regimes

\begin{tabular}{ll}
\hline Clinical Lab Parameters & $\begin{array}{l}\text { COVID-19 } \\
\text { Categories }\end{array}$ \\
\hline $\begin{array}{l}\text { Pre CP } \\
\text { Cl }\end{array}$ & Poderate \\
Post CP & Post CP \\
Hematological Parameters & \\
(CBC) & \\
Hemoglobin g/dl & $13.4 \pm 1.4$ \\
$12.7 \pm 1.4$ & $12.7 \pm 1.5$ \\
Total Leucocyte count $\times 10^{9}$ & $13.6 \pm 6.1$ \\
(TLC) & \\
12.1 \pm 4.0 & $12.5 \pm 6.2$ \\
Absolute Neutrophil Count & $10.5 \pm 6.6$ \\
(ANC) & \\
$9.4 \pm 4.4$ & $8.7 \pm 5.0$ \\
Absolute Lymphocyte Count & $1.5 \pm 1.3$ \\
(ALC) & \\
$2.7 \pm 1.1$ & $2.78 \pm 1.91$ \\
Platelets Count $\times 10^{9}$ & $227.5 \pm 6.3$ \\
$317 \pm 94.7$ & $350 \pm 9$ \\
&
\end{tabular}

\section{Biochemistry Markers}

Alanine aminotransferase $(\mathrm{ALT}) \mathrm{U} / \mathrm{L}$

$91.0 \pm 114$

$25.1 \pm 14.3$

Aspartate Aminotransferase (AST) U/L

\section{$21.0 \pm 14.9$}

Bilirubin $\mathrm{mg} / \mathrm{dl}$

$0.30 \pm 0.24$

Creatinine mg/dl

$1.1 \pm 0.59$

$\mathrm{LDH} U / \mathrm{L}$

$173 \pm 65$

\section{Inflammatory Markers}

C-Reactive Protein
(CRP) $\mathrm{mg} / \mathrm{L}$

$5.1 \pm 2.4$

Ferritin ng/ml

$272 \pm 126$

D-Dimer ng/ml

$1.6 \pm 0.64$

\section{Treatment}

Antibiotics

\begin{tabular}{|c|c|c|c|c|}
\hline Severe & Critical & & & \\
\hline$p$-value & Pre CP Cl & $p$-value & $\begin{array}{l}\text { Pre } \\
C P\end{array}$ & $\mathrm{Cl}$ \\
\hline
\end{tabular}

Post CP




Table 2 Changes in Lab findings and efficacy of CP in comparison to other experimental regimes (Continued)

\section{Clinical Lab Parameters COVID-19 Disease \\ Categories}

\begin{tabular}{|c|c|c|c|c|c|c|}
\hline 8 & 13 & 1 & & & & \\
\hline Corticosteroid & 14 & $0.165^{d}$ & 27 & $0.195^{d}$ & 2 & $0.500^{d}$ \\
\hline 11 & 23 & 1 & & & & \\
\hline
\end{tabular}

'Paired sample t-test

${ }^{\mathrm{d}}$ Fisher's Exact test

"Significant value

(A)

$$
\text { RR }
$$<smiles></smiles>

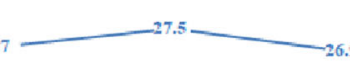<smiles></smiles>


D -1
D 1
D3
D5
D7
D9

(B)

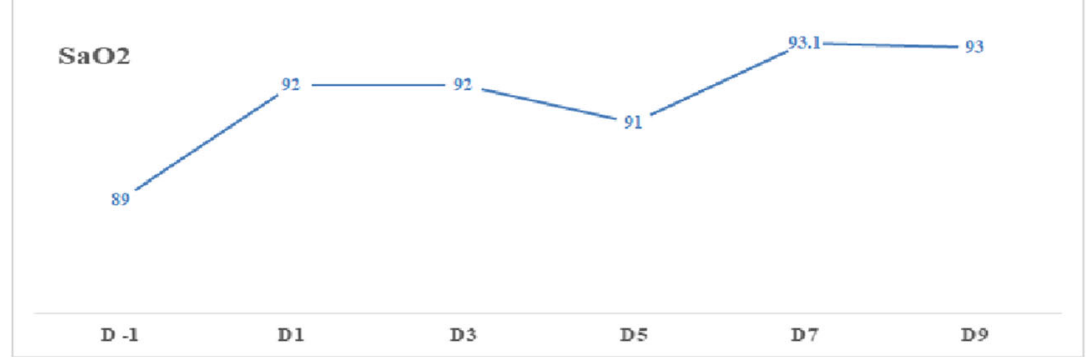

(C)



(D)

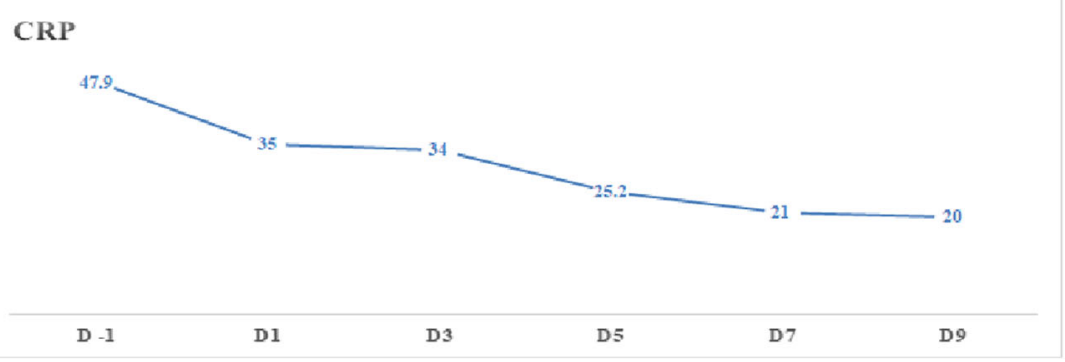

Fig. 2 Manifests the initial response as decline in raised values of Respiratory rate, CRP, ferritin, and increased Oxygen saturation after CP administration in first $72 \mathrm{~h}$ 

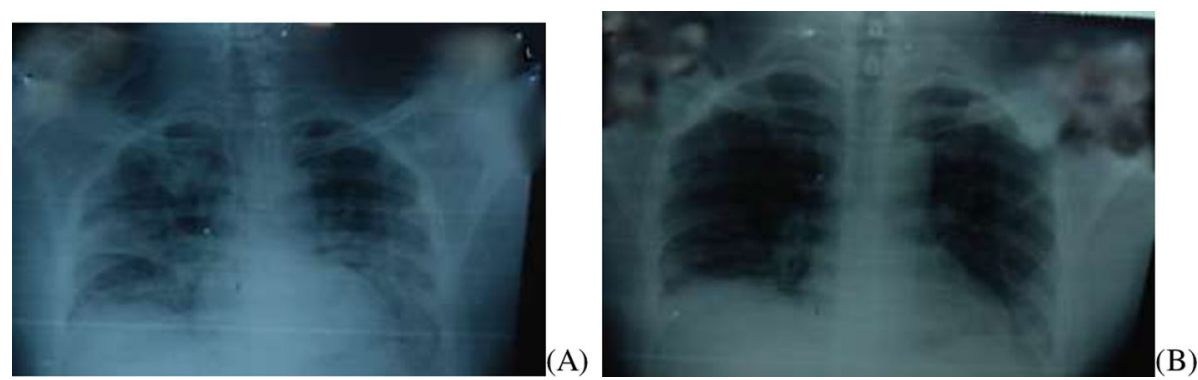

Fig. 3 Radiological findings on chest X-ray of COVID-19 positive patient. A Pre-CP findings exhibits patchy infiltrations bilaterally. B Post CP CXR shows absorption of pulmonary infiltrates and improvement bilaterally on 5th day of $\mathrm{CP}$ transfusion

Interestingly, one patient was successfully extubated from ventilator on fifth day of post $\mathrm{CP}$ and manifested marked improvement in oxygen saturation and chest $\mathrm{x}$ ray findings. The other patient on ventilator receiving $\mathrm{CP}$ treatment died of ventilator related complication including excessive cytokine storming as confirmed by deranged inflammatory markers (Fig. 4).

\section{Discussion}

This MEURI designed study was conducted for the assessment of CP's safety and usefulness for COVID-19 hospitalized patients in Pakistan and achievement of primary and secondary end points i.e., 'improvement in symptoms as well as change in clinical severity of disease' and 'halting disease progression'. The complete viral clearing was confirmed by negative RT-PCR. Both primary and secondary endpoints were achieved in moderately severe (100\%) and severe COVID-19 patients (82.35\%) with no severe adverse events. The oxygen saturation was markedly improved within 3 days after receiving a single dose of $\mathrm{CP}$ transfusion with improved pulmonary lesions. The SARS CoV2 causes pneumonia possibly due to its rapid replication leading to massive infiltration of neutrophils and lymphocytes. The accumulation of pro-inflammatory cytokines in alveoli may cause cytokine storm leading to acute lung injury and acute respiratory distress syndrome (ARDS) in most patients [2]. COVID-19 is characterized by tissue injury as a result of alveolar capillary micro thrombi more prevalent in COVID patients leading to tissue hypoxia [18] and in our dataset raised levels of non-specific tissue injury marker i.e. $\mathrm{LDH}$ was observed in patients before $\mathrm{CP}$ treatment which sharply reduced after $\mathrm{CP}$ transfusion (Table 2 [10]). The overall steady improvement in



Fig. 4 Survival curve of moderate, severe, and critical COVID-19 CP recipient patients through Kaplan-Meier analysis 
lymphocyte counts, ferritin, D-Dimer, pulmonary lesions and ultimately marked betterment in oxygen saturation along with clear chest X-ray possibly occurred due to neutralizing antibodies in $\mathrm{CP}$ that lead to cessation of replication and eradication of damaging virus from the blood stream as well as lung parenchyma [13]. This possible mechanism also aided in clearance of virus resulting in negative PCR in $80 \%$ of patients on fifth day of transfusion of $\mathrm{CP}$. This rapid action of $\mathrm{CP}$ against COVID - 19 shows that it is indeed a promising candidate for treatment of COVID-19 with rare side effects. The hemoglobin in our results remained in norms except in critical group where it was $9.8 \mathrm{~g} / \mathrm{dL}$. The suggested mechanism for low $\mathrm{Hb}$ in critical COVID patients may be due to viral inhibition of heme metabolism or virus-induced hemoglobin denaturation [19].

A recent clinical trial observed sustained or improved supplemental oxygen requirements (odds ratio: $0.86 ; p=$ 0.028 ) which is in-line with present study [20]. A considerably important factor is the time of $\mathrm{CP}$ infusion. In a previous study on SARS, better treatment outcome was achieved on $\mathrm{CP}$ infusion before 14th day of infection. Similarly, in the present study, CP was transfused between 3 and 7 days of infection. SARS CoV2 infections has been reported to be fatal in elderly age group with co-morbidities such as hypertension, diabetes, asthma [17]. In the present study, the patients who could not survive even after timely $\mathrm{CP}$ treatment were either elderly or with underlying medical conditions or both. Although one patient had asthma, but he recovered due to timely CP treatment [21]. Asthma was initially thought to be a risk factor for fatal outcome in COVID-19 but it has been reported to have protective effect in recent literature [22]. SOFA scoring applied to the recipients who expired post $\mathrm{CP}$ transfusion, supported the fact that patients on ventilator and those who received delayed $\mathrm{CP}$ transfusion after a week or more of hospitalization had poor prognosis as compared to those who were not on ventilator and received $\mathrm{CP}$ therapy much earlier within 7 days of hospitalization. Hence it can be stated that prolonged stay and delayed $\mathrm{CP}$ therapy might lead to the development of multi organ damage leading to complications specifically in patients on ventilator and ultimately resulted in increased number of deaths. Transfusion related acute lung injury has been reported in the past in a female $\mathrm{CP}$ recipient for treatment of Ebola [13]. In the present study, no such or other adverse events were recorded for any of the $\mathrm{CP}$ treated patients. Recent CP trials on COVID-19 patients from China and USA also reported no side effects of $\mathrm{CP}$ transfusion.

Dose of CP for efficient treatment is an important factor $[12,14]$. Suboptimal dose CP may have rare possibility of suppression of recipient's innate immune response against virus resulting in antibody induced enhancement of infection. The CP donor screening for SARS CoV2 via PCR is recommended to exclude the possibility of viral transmission to recipient possibly increasing viral load in already infected patients. During the present study, this precautionary screening was performed for every donor.

Hence, the CP transfusion so far, seemed to be the safest modality of managing COVID-19 patients and the hall mark of this therapy is timely infusion and selection of category of recipients. No promising results were obtained in patients with delayed infusion and critical group on ventilator along with concomitant comorbid. Limitation of this study is that there was no randomized controlled group here, so no inference on efficacy of $\mathrm{CP}$ can be drawn. Randomized controlled trials are needed to study the benefits or disadvantages of $\mathrm{CP}$ transfusion in COVID-19 patients.

\section{Conclusion}

Based on the current findings it can be concluded that the CP can be considered as safe, low cost and handy investigational treatment option with very uncommon side effects during the present state of crisis for management of moderate to severe COVID-19 patients. No severe adverse events were observed in patients receiving $\mathrm{CP}$ treatment. However, the time of initiation of $\mathrm{CP}$ treatment is critical. The sooner it is deployed, the better and quicker would be the desired outcomes.

\section{Abbreviations}

CP: Convalescent Plasma; PCR: Polymerase Chain Reaction; TRALI: Transfusion Related Acute Lung Injury; ANC: Absolute Neutrophil Counts; LDH: Lactate Dehydrogenase; SOFA: Sequential Organ Failure Assessment

\section{Acknowledgements}

We are thankful to our collaborative institutions including Prof. Dr. Ikram din Ujjan (Liaquat University of Medical and Health Sciences, Jamshoro), Dr. Sheikh Nadeem Samad (RBC, Quetta), Dr. Rashid Naseem (Darul Sehat Hospital, Karachi), Prof. Dr. Anjum Rehman (Lyari General Hospital, Karachi), Dr. Muhammad Nasir Khoso and Dr. Ammara Khan (South city Hospital, Karachi) and Dr. Vinod Kumar (Tabba Heart Hospital) for their unconditional support in data sharing, Passive Immunization squad especially Dr. Syed Jawad Hassan and paramedical team for their generous contribution. We would like to thank Dr. Abdul Rashid Khan of Pharmacy Division of DRAP and Dr. Durrenaz Jamal and Dr. Meesam Abbas of Sindh Blood Transfusion Authority for their constant support. There is no conflict of interest to disclose.

\section{Authors' contributions}

All authors have read and approved the manuscript and ensure that this is the case. TN and SNM: Wrote the manuscript. SM3, LM, BD, JA, AM, RS, SI, M.B.A, SM1, SA provided patients' data. NF and SM2: Statistical analysis of the data. AN and TS critical revision of manuscript. TS project Head.

\section{Funding}

Grant No: NIBD/2019/1010, Hilton Pharmaceuticals, and Karachi Pakistan.

\section{Availability of data and materials}

The data that support the findings of this study are available from the corresponding author, upon request. 


\section{Declarations}

\section{Ethics approval and consent to participate}

The study has been approved by the National Bioethics Committee and institutional ethics committee at NIBD and participants have given written consent to participate in this study.

\section{Consent for publication}

Not Applicable.

\section{Competing interests}

There are no conflict of interest to disclose.

\section{Author details}

${ }^{1}$ National Institute of Blood Diseases \& Bone Marrow Transplantation, Karachi, Pakistan. ${ }^{2}$ Hayatabad Medical Complex, Peshawar, Pakistan. ${ }^{3}$ Rawalpindi Medical University, Rawalpindi, Pakistan. ${ }^{4}$ Liaquat University of Medical and Health Sciences, Jamshoro, Pakistan. ${ }^{5}$ University of Health Sciences, Lahore, Pakistan. ${ }^{6}$ The Indus Hospital, Karachi, Pakistan. ${ }^{7}$ Regional Blood Center, Sukkur, Pakistan. ${ }^{8}$ Orthopedic and Medical Institute (OMI) Hospital, Karachi, Pakistan. ${ }^{9}$ Liaquat National Hospital, Karachi, Pakistan. ${ }^{10}$ Shah Medical Center, Karachi, Pakistan. ${ }^{11}$ Saifee Hospital, Karachi, Pakistan. ${ }^{12}$ Patel Hospital, Karachi, Pakistan.

Received: 16 February 2021 Accepted: 20 July 2021

Published online: 27 September 2021

\section{References}

1. Siddell SG. The coronaviridae. Springer. 1995:1-10. https://www.springer. com/gp/book/9780306449727.

2. Lu R, Zhao X, Li J, Niu P, Yang B, Wu H, et al. Genomic characterisation and epidemiology of 2019 novel coronavirus: implications for virus origins and receptor binding. Lancet. 2020;395(10224):565-74. https://doi.org/10.1016/ S0140-6736(20)30251-8

3. Ali I, Alharbi OML. COVID-19: Disease, management, treatment, and social impact. Sci Total Environ. 2020;728:138861. https://doi.org/10.1016/j. scitotenv.2020.138861. Epub 2020 Apr 22.

4. Zhu Z, Lu Z, Xu T, Chen C, Yang G, Zha T, et al. Arbidol monotherapy is superior to lopinavir/ritonavir in treating COVID-19. J Infect. 2020;81(1):e21e3. https://doi.org/10.1016/j.jinf.2020.03.060.

5. Wooding DJ, Bach H. Treatment of COVID-19 with convalescent plasma: lessons from past coronavirus outbreaks. Clin Microbiol Infect. 2020;26(10): 1436-46. https://doi.org/10.1016/j.cmi.2020.08.005.

6. Tanne JH. Covid-19: FDA approves use of convalescent plasma to treat critically ill patients. BMJ. 2020;368:m1256.

7. Widders A, Broom A, Broom J. SARS-CoV-2: The viral shedding vs infectivity dilemma. Infection, Disease \& Health, 2020:25(3):210-5.

8. Rojas M, Rodríguez Y, Monsalve D, Acosta-Ampudia Y, Camacho B, Gallo J et al. Convalescent plasma in Covid-19: Possible mechanisms of action. Autoimmun. Rev. 2020;19(7):102554.

9. Ko J-H, Seok H, Cho SY, Ha YE, Baek JY, Kim SH, et al. Challenges of convalescent plasma infusion therapy in Middle East respiratory coronavirus infection: a single centre experience. Antivir Ther. 2018;23(7):617-22. https:// doi.org/10.3851/IMP3243

10. Duan K, Liu B, Li C, Zhang H, Yu T, Qu J, et al. Effectiveness of convalescent plasma therapy in severe COVID-19 patients. Proc Natl Acad Sci. 2020; 117(17):9490-6. https://doi.org/10.1073/pnas.2004168117.

11. Siracusano G, Pastori C, Lopalco L. Humoral immune responses in COVID-19 patients: a window on the state of the art. Front Immunol. 2020;11. https:// doi.org/10.3389/fimmu.2020.01049.

12. Erika P, Domenica Z, Paolo I, Luca R, Giulia L, Alessandro D, et al. Lactate dehydrogenase and $\mathrm{C}$-reactive protein as predictors of respiratory failure in CoVID-19 patients. Clinca Chimica Acta. 2020;509:135-8.

13. Zeng F, Dai C, Cai P, Wang J, Xu L, Li J, et al. A comparison study of SARS CoV-2 lgG antibody between male and female COVID-19 patients: a possible reason underlying different outcome between sex. J Med Virol. 2020.

14. Perumallapalli AK, Prasad S, Singh D, Priyadarshini A, Naidu SA. Use of Convalescent Plasma in COVID-19. PUMRJ [Internet]. 1 Aug. 2020;3(SPECIAL). Available from:https://www.praxisug.com/index.php/Praxis/article/view/92.
15. Zhao Q, He Y. Challenges of convalescent plasma therapy on COVID-19. J Clin Virol. 2020;127:104358. https://doi.org/10.1016/j.jcv.2020.104358.

16. Feng $Y$, Ling $Y$, Bai T, Xie Y, Huang J, Li J, et al. COVID-19 with different severities: a multicenter study of clinical features. Am J Respir Crit Care Med. 2020;201(11):1380-8. https://doi.org/10.1164/rccm.202002-04450C.

17. Organization W. Clinical management of COVID-19: interim guidance, 27 May 2020 [Internet]. Apps.who.int. 2021. [cited 10 January 2021]. Available from: https://apps.who.int/iris/handle/10665/332196.

18. Ackermann $M$, Verleden SE, Kuehnel $M$, Haverich $A$, Welte $T$, Laenger $F$, et al. Pulmonary vascular endothelialitis, thrombosis, and angiogenesis in Covid19. N Engl J Med. 2020;383(2):120-8. https://doi.org/10.1056/NEJMoa201 5432

19. Cavezzi A, Troiani E, Corrao S. COVID-19: Hemoglobin, Iron, and Hypoxia beyond Inflammation. A Narrative Review. Clinics and Practice. 2020;10(2): 24-30.

20. Liu S, Lin H, Baine I, Wajnberg A, Gumprecht J, Rahman F et al. Convalescent plasma treatment of severe COVID-19: a propensity scorematched control study. Nature Medicine. 2020;26(11):1708-13.

21. Liu ST, Aberg JA. Convalescent plasma in patients hospitalised with COVID19. Lancet. 2021;397(10289):2024-5. https://doi.org/10.1016/S0140-6736(21 )01064-3.

22. Lommatzsch M, Stoll P, Virchow JC. COVID-19 in a patient with severe asthma treated with Omalizumab. Allergy. 2020;75(10):2705-8. https://doi. org/10.1111/all.14456.

\section{Publisher's Note}

Springer Nature remains neutral with regard to jurisdictional claims in published maps and institutional affiliations.

\section{Ready to submit your research? Choose BMC and benefit from:}

- fast, convenient online submission

- thorough peer review by experienced researchers in your field

- rapid publication on acceptance

- support for research data, including large and complex data types

- gold Open Access which fosters wider collaboration and increased citations

- maximum visibility for your research: over $100 \mathrm{M}$ website views per year

At BMC, research is always in progress.

Learn more biomedcentral.com/submissions 